\title{
THE NEED OF COUPLED DIFFERENTIAL AND INTEGRAL SPECTRAL RADIATION MEASUREMENTS (U)
}

by J.F. Zino

Westinghouse Savannah River Company

Savannah River Site

Aiken, South Carolina 29808

Other Authors:

\section{RECEIVED \\ JUN $O 91993$ OSTI}

A paper proposed for Presentation/Publication

at/in the 1993 ANS Topical Meeting on Physics and Methods in Criticality Safety Nashville, TN

$09 / 19 / 93$

This paper was prepared in connection with work done under Contract No. DE-AC09-89SR18035 with the U. S. Department of Energy. By acceptance of this paper, the publisher and/or recipient acknowledges the U. S. Government's right to retain a nonexclusive, royalty-free license in and to any copyright covering this paper, along with the right to reproduce and to authorize others to reproduce all or part of the copyrighted paper. 


\section{DISCLAIMER}

This report was prepared as an account of work sponsored by an agency of the United States.Government. Neither the United States Government nor any agency thereof, nor any of their employees, makes any wartanty, express or implied, or assumes any legal liability or responsibility for the accuracy, completeness, or usefulness of any information, apparatus. product, or process disclosed, or represents that its use would not infringe privately owned rights. Reference herein to any specific commercial product, process, or service by trade name, trademark, manufacturer, or otherwise does not necessarily constitute or imply its endorsement, recommendation, or favoring by the United States Government or any agency thereof. The views and opinions of authors expressed herein do not necessarily state or reflect those of the United States Government or any agency thereof.

This report has been reproduced directly from the best available copy.

Available to DOE and DOE contractors from the Office of Scientific and Technical Information, P.O. Box 62, Oak Ridge, TN 37831; prices available from (615) 576-8401, FTS 626-8401.

Available to the public from the National Technical Information Service, U.S. Department of Commerce, 5285 Port Royal Rd., Springfieid, VA 22161. 
The Need for Coupled Differential and Integral Spectral Radiation Measurements (U)

b y

J.F. Zino

Westinghouse Savannah River Company

Savannah River Technology Center

Building 773-22A

Aiken, SC 29808

\section{Abstract}

The criticality safety community has historically directed a significant amount of effort toward attempting to quantify the integral behavior of fissioning systems via critical and subcritical experimental measurements. Some typical integral characteristics include critical masses, geometries, or concentrations for particular fissile isotopes in different chemical forms.

While information such as this can be invaluable for determining criticality safety operating limits and for benchmarking computational methods, it is only a part of what is necessary for analyzing criticality accident alarm detectors. These analyses also require determination of the differential behavior of the leakage radiation (neutron and/or photon) emanating from the source, and an integral estimate of the corresponding detector dose response.

This paper will address part of the work done at the Savannah River Technology Center to validate version 4.2 of the Monte Carlo transport code $\mathrm{MCNP}_{[1]}$ for application to criticality detector response analysis. Additionally, the paper will discuss some observations about existing experimental data which can be used for code validation, as well as the need for further experiments.

This article was prepared in connection with work done under Contract No. DEAC09-89SR18035 with the U.S. Department of Energy. By acceptance of this article, the publisher and/or recipient acknowledges the U.S. Government's right to retain a nonexclusive, royalty-free license in and to any copyright covering this article, along with the right to reproduce and to authorize others to reproduce all or part of the copyrighted article. 


\section{Introduction}

As part of an overall program to improve criticality accident alarm placement documentation at the Savannah River Site (SRS), a sitewide initiative was undertaken. The Savannah River Technology Center of the Westinghouse Savannah River Company was assigned the responsibility of developing new calculational methodologies to perform the detector placement analyses. In addition, the Technology Center also performed and documented the alarm placement analyses, and determined evacuation zones as required by DOE order 5480.5 .

In order to establish the technical basis for using calculational methods to evaluate the coverage areas of criticality detector systems, a survey of the existing experimental data to validate the computer codes must be done. The validation of computer codes requires experimental data which characterizes the leakage source behavior of the criticality event, as well as quantifies the dose response behavior of detectors from this source.

\section{Discussion}

\section{Fission Source Leakage}

There have been numerous critical (and subcritical) experimental measurements performed throughout the nuclear industry over the past fifty years. These experiments have focused primarily on quantifying some integral characteristic (usually $k_{\text {eff }}$ ) of the system as a function of several independent variables. It was these experiments which established the criticality safety technical basis for many of the nuclear processes which have operated to this day. However, there has been comparatively little experimental work done to quantify the behavior of these critical fissioning systems treating them purely as neutron and photon radiation sources. Only a few of the very early experiments (Jezebel and Godiva in the 1950's) and one relatively recent experiment (SHEBA in the 1980's) involved characterization of the radiation leakage spectra from critical fissioning systems.

The Jezebel experimental set-up $[2 ; 3 ; 4]$ is essentially a highly enriched $(95.5 \% 239 \mathrm{Pu}, 4.5 \% 240 \mathrm{Pu})$ metal sphere of radius $6.3842 \mathrm{~cm}$. The 
metal has a density of $15.66 \mathrm{~g} / \mathrm{cc}$, and the total mass of Pu metal is approximately $16.5 \mathrm{Kg}$. The sphere is encased in a thin nickel coating and there is modest steel support structure surrounding the assembly. The core is suspended approximately 13 feet above a concrete floor which provides minimal neutron reflection.

The Godiva $[5 ; 6]$ experimental configuration is the $235 \mathrm{U}$ analog to Jezebel. It is a bare, spherical, high-enriched $(93.0 \% 235 \mathrm{U}, 6.0 \% 238 \mathrm{U}$, $1.0 \%{ }^{234} \mathrm{U}$ ) metal system of radius $8.7313 \mathrm{~cm}$ with a metal density of $19.0 \mathrm{~g} / \mathrm{cc}$. The experimental configuration is similar to that of Jezebel with a steel coating and nominal steel structural supports.

Simple models of these two systems were created with MCNP for the purpose of comparing measured and calculated neutron leakage spectra. Figures 1 and 2 show the results of the benchmark calculations [7]. The results indicate good agreement between the measured and MCNP calculated neutron behavior with 1 to $10 \%$ error for most data points. The one standard deviation $(1 \sigma)$ statistical uncertainties for the Monte Carlo calculations were $<2 \%$ for all cases.

The most current and relevant series of open literature experimental measurements $[8 ; 9]$ which consider the leakage radiation behavior from critical fissioning systems were performed with SHEBA (Solution High Energy Burst Assembly) at Los Alamos during the early 1980's (Figure 3). SHEBA is a solution critical system employing low enriched $(4.95 \%) 235 \mathrm{U}$ in fluoride form. The assembly is essentially a cylindrical 304SS tank with an outer diameter of 55.88 $\mathrm{cm}$, a wall thickness of $0.635 \mathrm{~cm}$, and a height of approximately 104 $\mathrm{cm}$. There is a central safety rod position (hollow during operation) which has a $7.62 \mathrm{~cm}$ diameter and a wall thickness of $0.635 \mathrm{~cm}$. The system is filled with a fuel solution of $\mathrm{UO}_{2} \mathrm{~F}_{2}$ (density of $2.16 \mathrm{~g} / \mathrm{cc}$ ), with a $235 \mathrm{U}$ content of $1.04 \mathrm{~g} / \mathrm{cc}$.

These experiments were designed primarily to investigate the neutron and photon leakage spectra from a solution critical system, to estimate the $\mathrm{n} / \gamma$ ratios for different solution types, and to calibrate criticality accident alarm systems. A detailed, 3-D MCNP model of SHEBA was created and the radiation leakage through a surface $5 \mathrm{~m}$ from the tank was calculated for a simulated critical solution level in the tank. Figures 4 and 5 show the results of neutron and photon leakage spectrum calculations versus measurement $[10 ; 11]$. Agreement 
is generally good with the exception of several data points in the higher energy ranges where differences as large as $>100 \%$ are seen.

Undoubtedly there is more data on criticality leakage source measurements performed throughout the nuclear industry than presented in this brief discussion. However, it is interesting to note that compared to experiments which were designed to establish criticality safety operating limits, there have been relatively few experiments which have directly measured radiation leakage from criticality source systems.

\section{Detector Response}

The second type of experimental data needed to benchmark codes for criticality alarm analysis is radiation detector response data. Treating the criticality event as a radiation source enables the analyst to perform a "shielding type" detector dose response calculation for the various criticality detectors located near the postulated event. While experimental shielding measurements have a history equally as long as criticality measurements in the nuclear industry, comparatively few experiments have been performed using criticality fission source terms.

A traditional method of testing the performance of criticality accident alarm systems is to put them through a series of "burst" response tests to determine if the electric/mechanical aspects of the detection system are able to meet the criteria outlined in ANS 8.3 [12]. These tests can be performed at open area test sites (usually in a desert environment) or in a reactor facility where neutron and gamma-ray radiation fields are sufficient to alarm the detectors positioned at prescribed locations from the source. In many cases, the ability of the detection system to alarm in a certain amount of time, to a certain radiation dose rate is the only criteria used to determine the systems success. Characterization of the effects of the radiation spectra (both leaving the source and entering the detector) on the measured alarm system's response is usually not quantified.

\section{Observations/Recommendations}

The two previous discussions; (1) defining the criticality leakage source behavior and; (2) analyzing the remote detector dose response, have historically been treated as two separate problems. 
This approach of decoupling the source calculation from the transmission calculation has been used effectively in shield design work for many years since there is usually not much discontinuity of the radiation flux (and/or current) at the boundary which exists between the two parts of the problem. Because of this, most experiments which have been designed to test criticality accideitt alarm systems have also either focused on determining the leakage source or calculating remote detector response; but not both simultaneously.

Since both the differential behavior of the leakage radiation and the integral behavior of a remote detector response depend on many of the same system variables for a critical fissioning system, a well designed benchmark quality experiment which directly couples these two characteristics is needed. This is particularly true for unmoderated and/or unreflected (i.e., bare) metal systems for which very little openly published experimental data could be found.

An example experiment would be one in which a critical source configuration would be operated at a steady-state power level for a certain time in an semi-open air environment (to minimize room reflection). The neutron and photon radiation leakage distributions would be measured near the surface of the source to derive the leakage spectra and to obtain an estimate of the $n / \gamma$ ratio. Simultaneously, neutron and gamma-ray detector responses would be measured at various distances from the reactor with various intervening shielding materials. The steady state reactor power level (or fission rate) can be used to derive a radiation source intensity needed for the dose rate calculation, and the effects of changing the differential behavior of the leakage source (i.e., through spectrum modifying materials) can be used to determine the induced changes on the detector dose rate response. Additionally, detailed measurements of the radiation spectra entering the detectors can be made to observe their behavior as a function of changes in the starting source spectra.

\section{Conclusions}

An outcome of the validation effort undertaken at the Savannah River Technology has been the observation that experimental data which is needed to properly benchmark computational methods for the analysis of criticality accident alarm systems is lacking (compared to experimental data for criticality safety). Valuable 
information on the radiation physics aspects of critical fissioning systems could be gained with a few, relatively simple, well designed benchmark quality experiments.

\section{References}

1. Briesmeister, J. F. (Ed), "MCNP-A General Monte Carlo Code for Neutron and Photon Transport, Version 3.b.", LA-7396, (1986)

2. Geer, W.U., Koontz, P.G., Orndoff, J.D., Paxton, H.C. "Hazards Evaluation for the Los Alamos Critical Assembly Facility", LAMS-2698, (1962)

3. Hansen, G.E., Paxton, H.C., "Reevaluated Critical Specifications of Some Los Alamos Fast-Neutron Systems", LA-4208, (1969)

4. Stewari, L., "Leakage Neutron Spectrum from a Bare $\mathrm{Pu}^{239}$ Critical Assembly", Nuclear Science \& Engineering, Vol. 8, pp. 595-597 (1960)

5. Jarvis, G.A., Linenberger, G.A., Orndoff, J.D., Paxton, H.C., "Two Plutonium Metal Critical Assemblies", Nuclear Science \& Engineering, Vol. 8, pp. 525-531 (1960)

6. Peterson, R.E., Newby, G.A., "An Unreflected U235 Critical Assembly", Nuclear Science \& Engineering, Vol. 1, pp. 112-125 (1956)

7. Zino, J.F., "Neutron and Photon Leakage Spectrum Benchmarking Calculations with MCNP (U)", WSRC-TR-92-180, (1992)

8. Malenfant, R.E., Forehand, H.M., Koelling, J.J., "SHEBA: A Solution Critical Assembly", Trans. Am. Nucl. Soc., Vol. 35, pp 279-280 (1980)

9. Malenfant, R.E., Forehand, H.M., "Facility Description of a Solution Critical Assembly: SHEBA", Trans. Am. Nucl. Soc., Vol. 39, pp. 555-557 (1981)

10. Thorngate, J.H., Rueppel, D.W., Griffith, R.V., "Neutron and Gamma-Ray Spectrum Measurements at the Los Alamos Critical 
Assembly SHEBA", Trans. Am. Nucl. Soc., Vol. 39, pp. 557-559 (1981)

11. Hankins, D.E., "Neutron and Gamma-Ray Dose Measurements at the Los Alamos Critical Assembly SHEBA", Trans. Am. Nucl. Soc., Vol. 39, pp. 559-560 (1981)

12. American National Standard, "Criticality Accident Alarm System", ANS 8.3, (1986) 


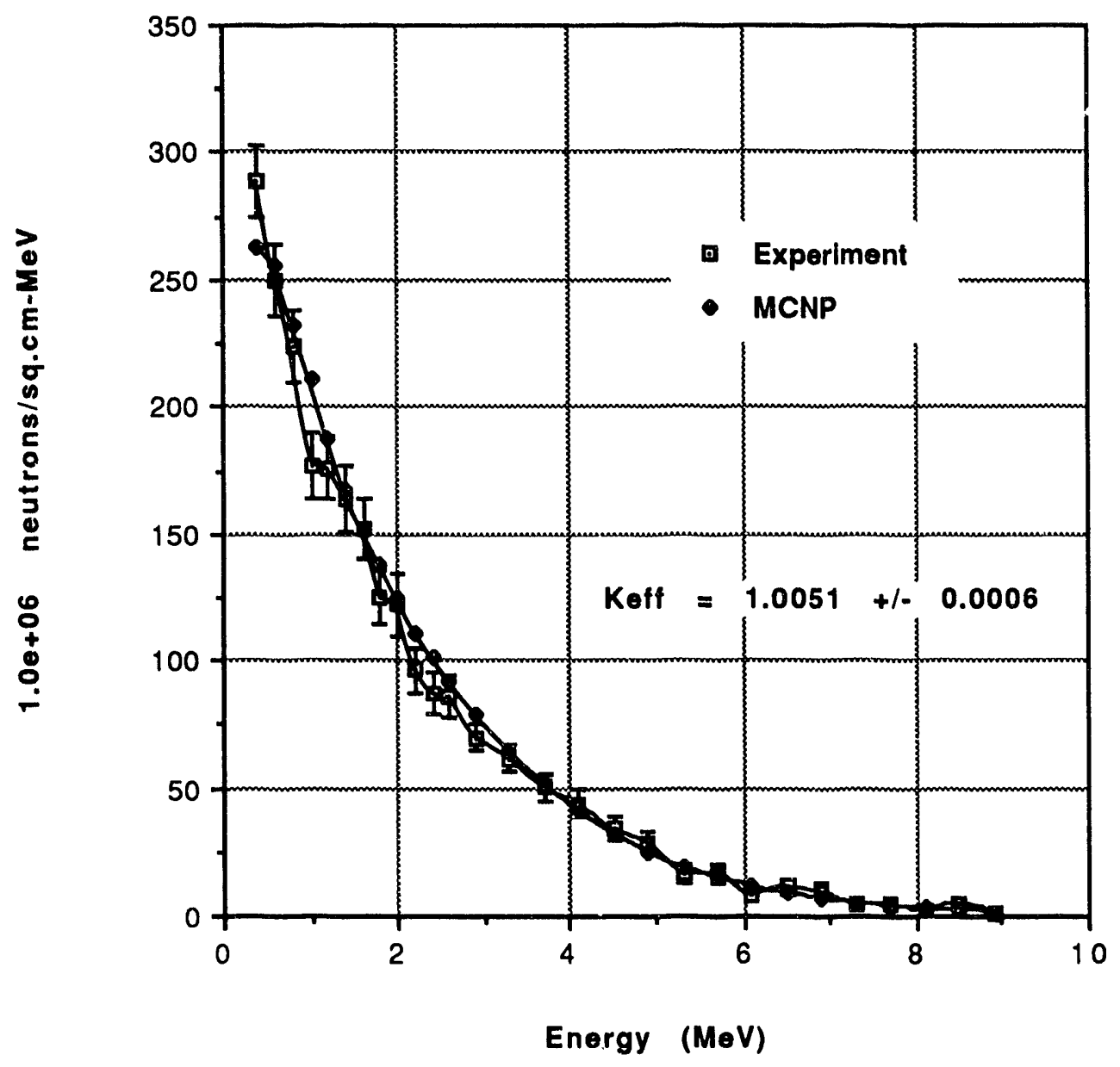

Figure 1.

Jezebel Neutron Leakage Spectra

MCNP vs. Experiment 


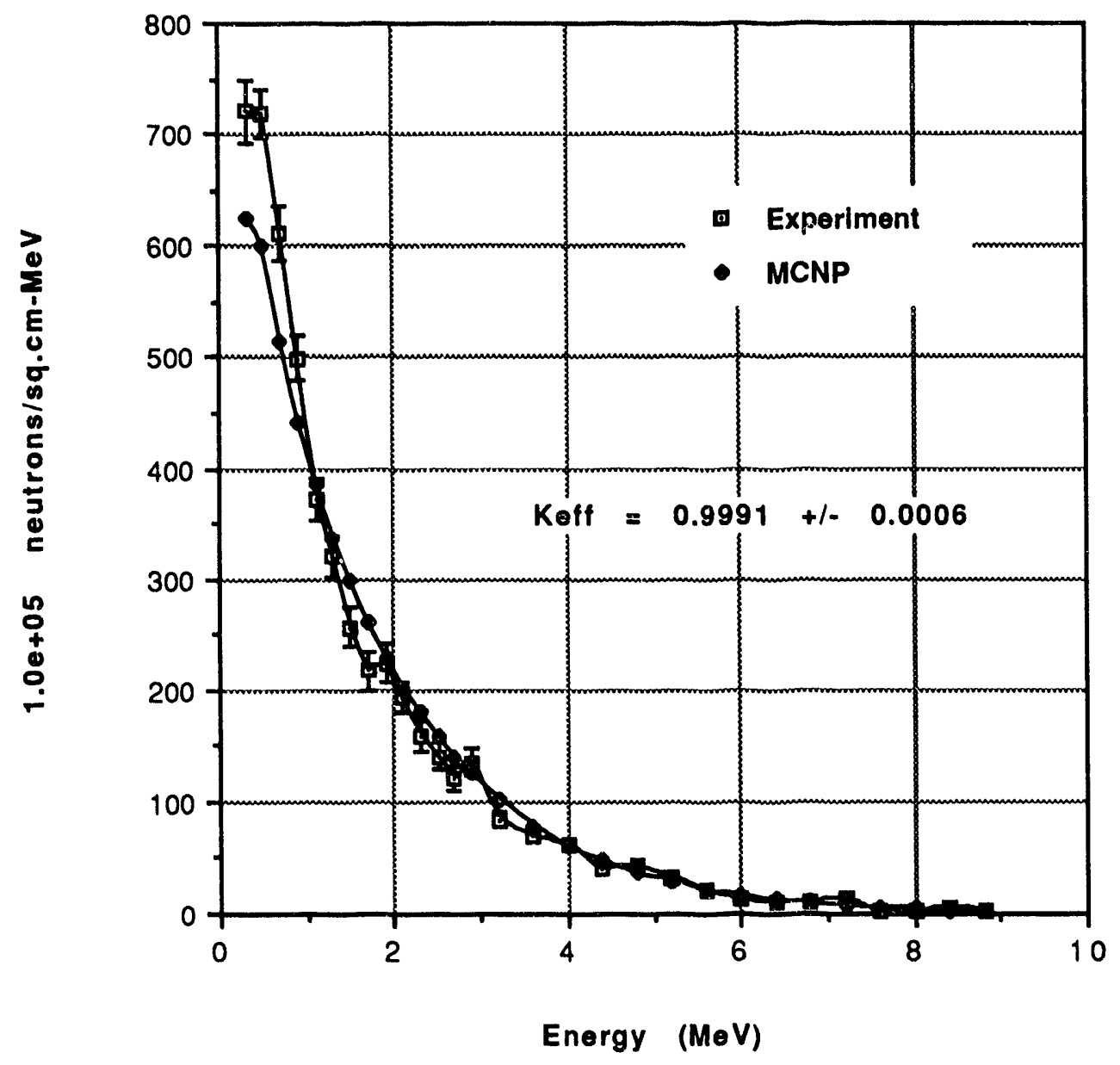

Figure 2.

Godiva Neutron Leakage Spectrum MCNP vs. Experiment 


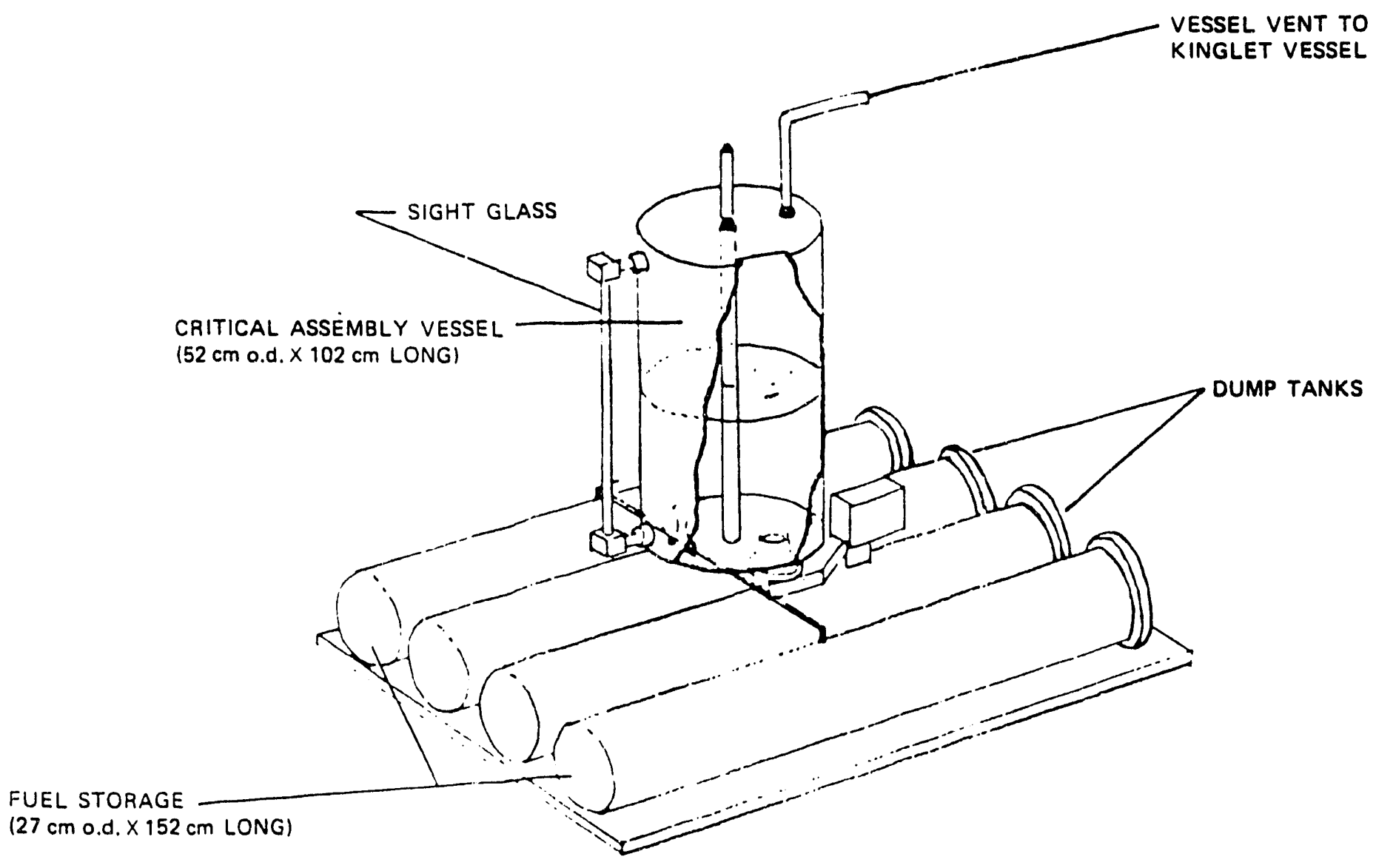

Figure 3.

Solution High Energy Burst Assembly (SHEBA) 


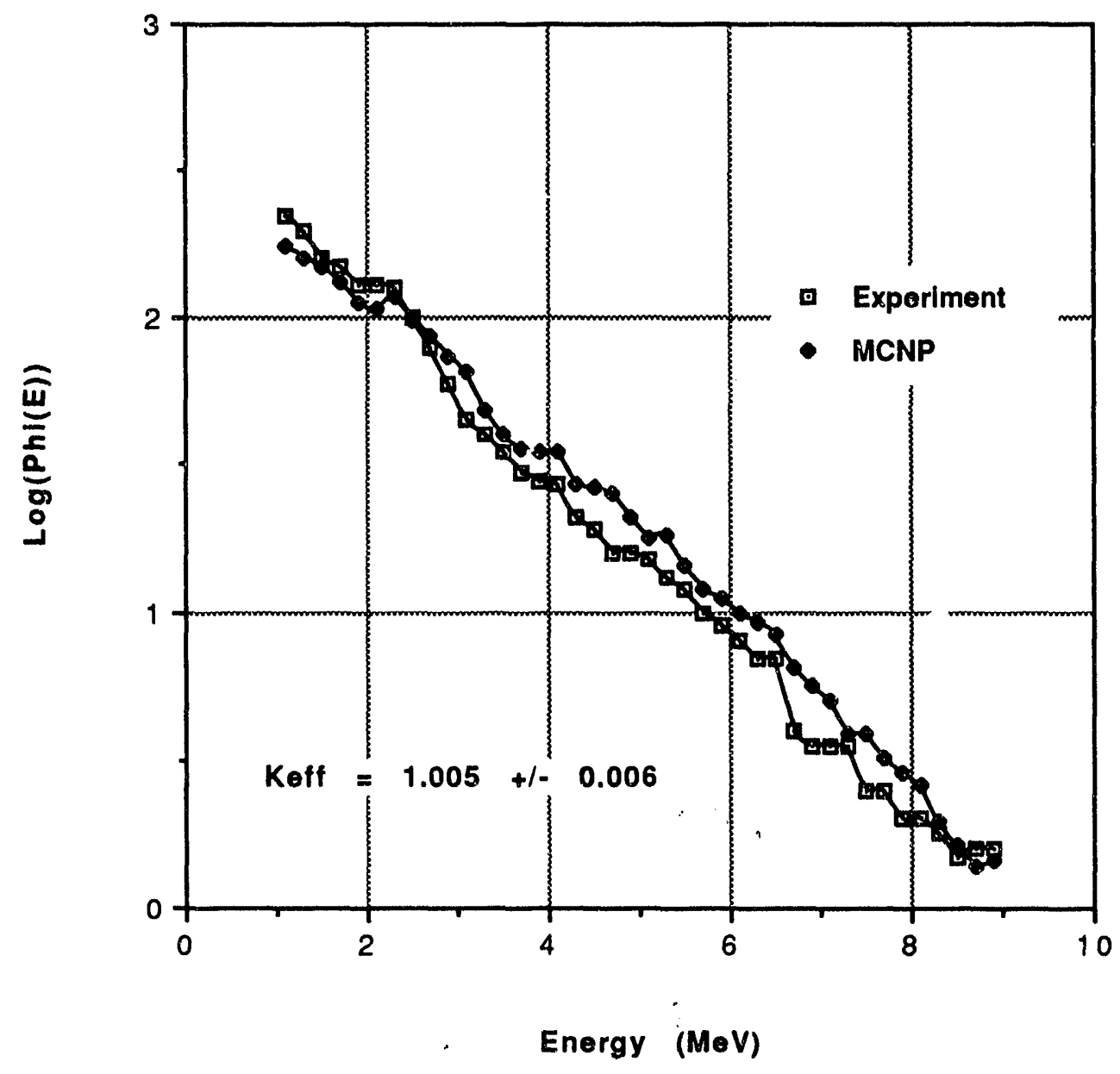

Figure 4.

SHEBA Neutron Leakage Spectra MCNP vs. Experiment 


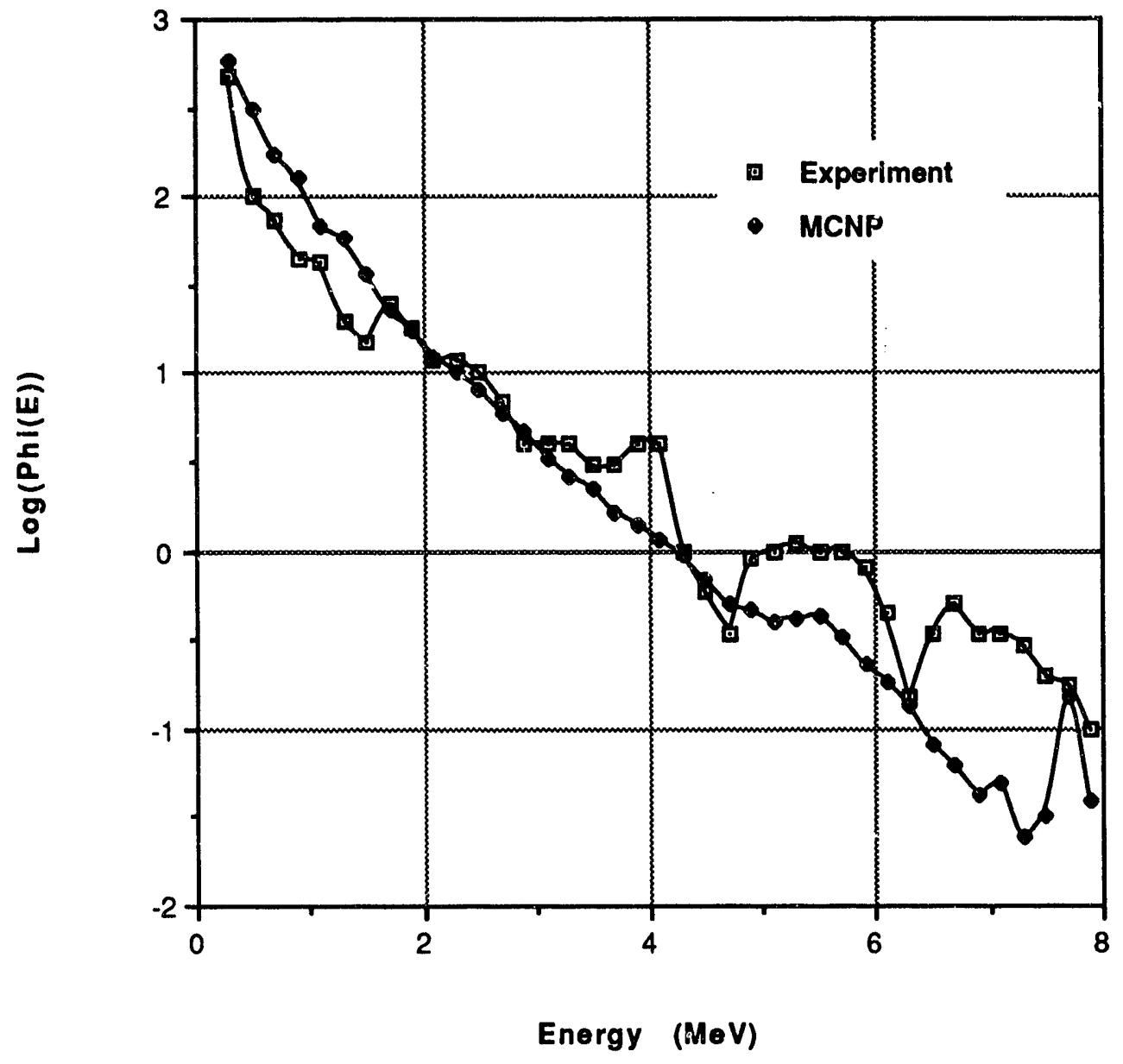

Figure 5.

SHEBA Photon Leakage Spectra MCNP vs. Experiment 

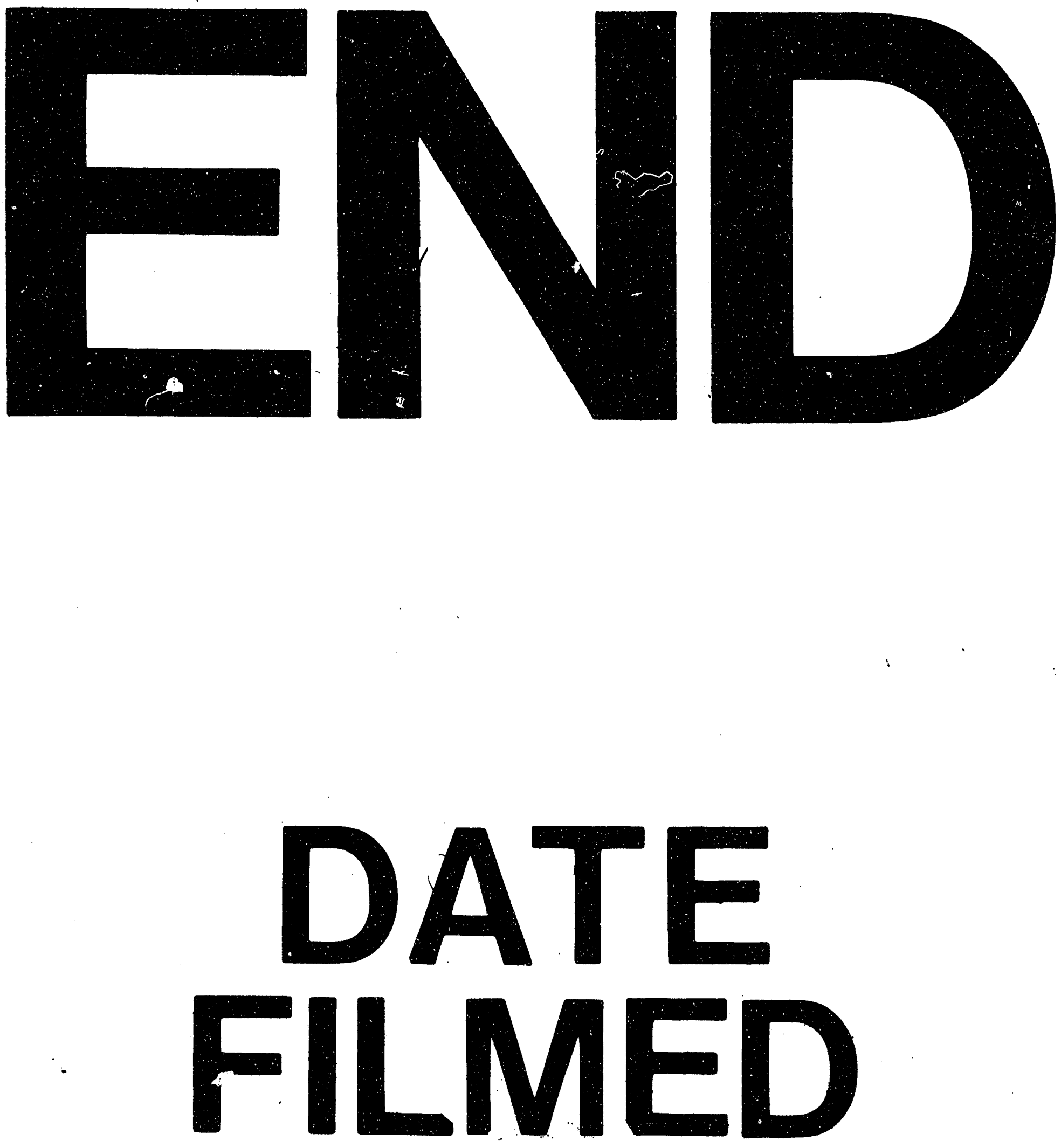

1

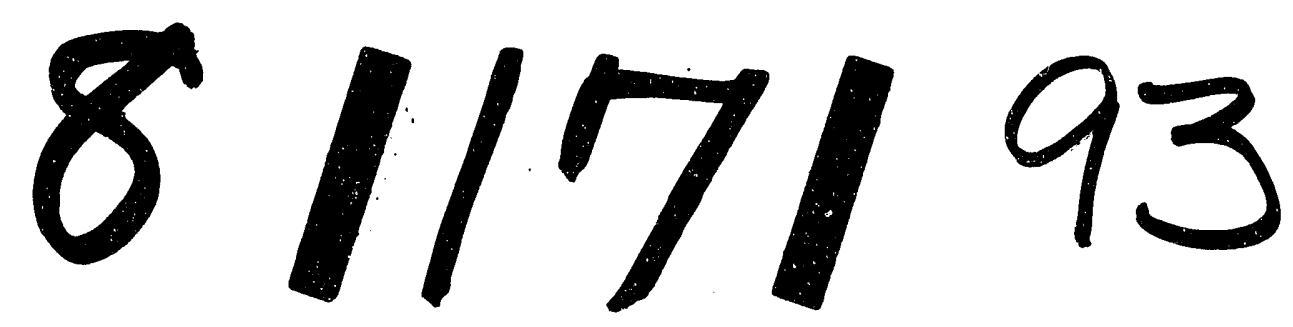


